\title{
Teacher's Voices Crying in the School Wilderness: Involvement of Secondary School Teachers in Curriculum Development in Zambia
}

\author{
Innocent Mutale Mulenga ${ }^{1, *} \&$ Christine Mwanza ${ }^{1}$ \\ ${ }^{1}$ The University of Zambia, School of Education, Department of Language and Social Sciences Education, Lusaka, \\ Zambia \\ *Correspondence: The University of Zambia (Great East Road Campus), School of Education, Department of \\ Language and Social Sciences Education, P.O Box 32379, Lusaka 10101, Zambia. Tel: 260-979-513-215. E-mail: \\ innocent.mulenga@ymail.com
}

Received: June 28, 2018

Accepted: July 29, 2018 Online Published: February 22, 2019

doi:10.5430/jct.v8n1p32

URL: https://doi.org/10.5430/jct.v8n1p32

\begin{abstract}
In Zambia, curriculum development for primary and secondary schools is done centrally. The Curriculum Development Centre (CDC), the institution placed with the responsibility of facilitating curriculum development, claims that the Zambian school curriculum is developed through a consultative and participatory approach through course and subject panels where teachers and other stakeholders are represented. However, there has been no empirical evidence to suggest the roles that teachers, who are the major implementers of the same curricular, are required to play in the development process. This study therefore, sought to establish perceptions of secondary school teachers on their role in the curriculum development process in Zambia. The concurrent embedded design of the mixed methods approach was employed with the qualitative approach dominating the study while the quantitative was used to add detail. Data from secondary school teachers was collected using questionnaires while interview guides were used for Head teachers. Raw data collected from interviews and questionnaires was analyzed using themes and descriptive statistics and then arranged into significant patterns so as to easily interpret and understand the essence of the data. The findings of the study clearly suggested that the majority of secondary school teachers in Lusaka were willing to participate in the curriculum development process, especially in situational analysis, in the formulation of educational objectives, in setting up the curriculum project, and in the writing of curriculum materials such as textbooks. From the study it was concluded that teachers were aware of some of the roles that they could play in the curriculum development but were not adequately involved in the development process.
\end{abstract}

Keywords: curriculum development, curriculum implementation, teacher involvement

\section{Introduction}

Bishop (1985: 190) observed that "a curriculum is only as good as the quality of its teachers." Indeed the significant role that teachers play in curriculum development and implementation cannot be over emphasized. Involvement of teachers in educational reform and innovation is crucial if educational programmes are to be effectively implemented at both national, regional and school levels. Whenever there is a need for curriculum development, the teacher's role and involvement come to the fore of necessity (Carl, 2012). It is evident from literature that there has been some differences, inconsistencies and gaps between the official, written, planned, intended and formal curriculum (Hale 2008; McNeil 2006; Ornstein \& Hunkins 2009; Posner 2004; Wiles, 2005; Weber, 2011). The teacher is definitely at the heart of the matter. One cannot proceed with an effective curriculum development process without the full co-operation and involvement of the teachers and local authorities. Teachers are the most critical resource in the provision of any formal education anywhere in the world as rightly put by Mulenga and Luangala (2015:39) that "they play a very important role in the facilitation of learners' acquisition of desirable knowledge, skills, values and attitudes". Moreover, teachers clearly understand and appreciate the needs of learners. Carless (1997) further emphasized that teachers' perceptions, attitudes and beliefs about the curriculum reform play a crucial role in the adoption, reinvention or rejection of a new or revised curriculum. Teachers therefore play a very important role in learner's educational development (Mulenga, 2015). However, much as teachers are perceived to be very essential in 
the curriculum development process and as evidenced by various literature, to the best knowledge of the researchers, little or no studies have been done in Zambia to establish teachers' perception on their roles in the curriculum development process. It is from this background that the study aimed at analysing teacher's roles in the curriculum development process in Zambia.

\section{Theoretical Framework}

This study was guided by the main idea behind the curriculum development and diffusion theory which emphasized that for any curriculum development model to become practical, the teacher has to be at the centre of the process irrespective of their limitations (Lawton, 1973). Ondiek (1986) described teachers as the key factor in education reform be it in short term changes or long term re-orientation of the school curriculum. It is on this basis that the study was guided by the this theory in maintaining that secondary school teachers being the direct implementers of the secondary school curriculum must be part of the curriculum development team.

\section{Method}

The data was collected through a mixed methods approach using the concurrent embedded design where the qualitative approach dominated the study. The concurrent embedded design enabled the researchers to gain perspectives from the different types of data and from different levels within the study (Creswell, 2009). In other words, the purpose of this design was to help answer various questions that required different type of data. The data that was collected was mostly descriptive in nature and it was used to get detailed information pertaining to the Teacher's role in curriculum development process in Zambia. Through the use of the concurrent embedded design, the researchers got answers to both the "what" and "why" questions and got a deeper understanding of the research problem by comparing the qualitative and quantitative findings. Creswell (2009) explained that when used in combination within the mixed methods approach, qualitative and quantitative methods complement each other and allow for a more detailed analysis of the research situation.

Data was collected from Lusaka district. According to the Ministry of General Education (MoGE), Lusaka has seven (7) zones. The researcher did a cluster sampling of one (1) secondary school per zone which was visited for the researchers. This method enabled the researchers to have a detailed sampling frame for selected clusters only rather than for the entire target area. Questionnaires were distributed to 10 teachers per school and interview schedules were used with the school head teachers in the selected schools. Qualitative data was analyzed according to themes were as quantitative data was analyzed using descriptive statistics.

\section{Results}

\subsection{Teachers' Willingness to Participate in Curriculum Development}

Before establishing possible roles that secondary school teachers could play in the school curriculum development process, it was cardinal to first of all determine if secondary school teachers were willing to participate in the curriculum development process. To this effect, teachers were asked to inidicate with a yes or no about their willingness to participate in the development of the secondary school curriculum if they were given a chance and opportunity. Figure 1 gives a summary of their responses.

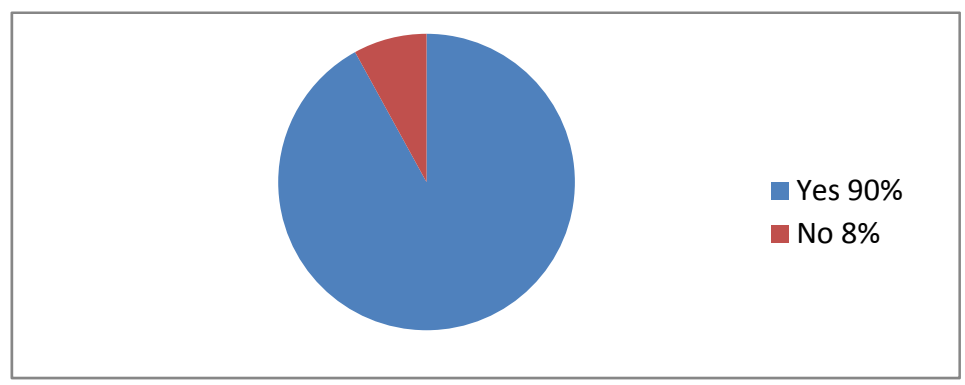

Figure 1. Percentage Distribution of Teacher's Willingness to Participate in Curriculum Development 
The majority of teachers $(90 \%)$ indicated "Yes", while only $8 \%$ declained. $2 \%$ of them did not pick any of the two options. Many teachers emphasized the need to participate because they thought that they were the final implementers of the curriculum and that they knew the challenges that learners and themselves faced. Some of them stated that;

- Being the final implementer of the curriculum it is important that I am involved.

- Teachers are the ones involved in curriculum implementation, its fit that they are involved in developing the curriculum to reduce on the challenges.

- Because I would first share my experience as I have been handling learners, fill up the gap and eventually it would be easy for me to implement the developed curriculum because I would have been involved from the beginning.

Additionally, teachers wanted to participate in the curriculum development process so as to address the challenges faced during the implementation. One teacher explained that;

I want to participate in the curriculum development process in order to address the challenges I encounter when teaching and when setting examination at grade 12 and because we are the ones who know what to teach and what pupils are able to do. We even know what teaching resouces should be used when teaching.

Experience in teaching and subject area was one of the reasons that emerged. One teacher indicated that he would want to participate in the curriculum development process because of the experience he had. This was noted when he said that;

Because I have taught for 20 years and trained to teach at both primary and secondary levels of education and apart from that I have seen programmes come and go and have known the reasons of this failure.

Other reasons that emerged for willingness of teachers to participate in curriculum development included to earn an allowance during the process while other respondents wanted to have an input in the materials that they would be using when teaching.

However, about $8 \%$ (see figure 1) of the respondents indicated that they would not participate in the development of the curriculum. One teacher indicated that,

I cannot participate because I need experience in the first place, so those whose experience is vast can.

Another one simply indicated that;

It is not motivating.

From the responses from the secondary school teachers, it can be noted that the majority of teachers were willing to participate in the development of the curriculum. Most of the teachers who were willing to participate in the development of the curriculum had their reasons connected to the effective implementation of the curriculum. These responses indicated that teachers were confident that given an opportunity to participate in the curriculum development process, they would contribute positively and they would consequently implement such a curriculum with ease.

\subsection{Stages at Which Teachers Should Be Involved in Curriculum Development Process}

It was clear from the responses that were provided on the willingness of teachers to participate in the curriculum development process that teachers were very much willing to participate for various reasons. We therefore wanted to establish specific stages that teachers were interested in participating during the curriculum development process. In trying to solicit this information teachers were thus asked to indicate at which stages of the curriculum development process they felt they could be involved in.

Most of them (56.9\%) indicated that they should be involved in situational analysis and formulation of educational objectives. Setting up the curriculum project and constructing the programme was indicated by $54.2 \%$ of the respondents and nearly five in ten of the respondents (51.4\%) indicated involvement at the programme improvement stage. $41.7 \%$ of them indicated that they should be involved in piloting the new programme in selected schools. Figure 2 presents a summary of the responses. 


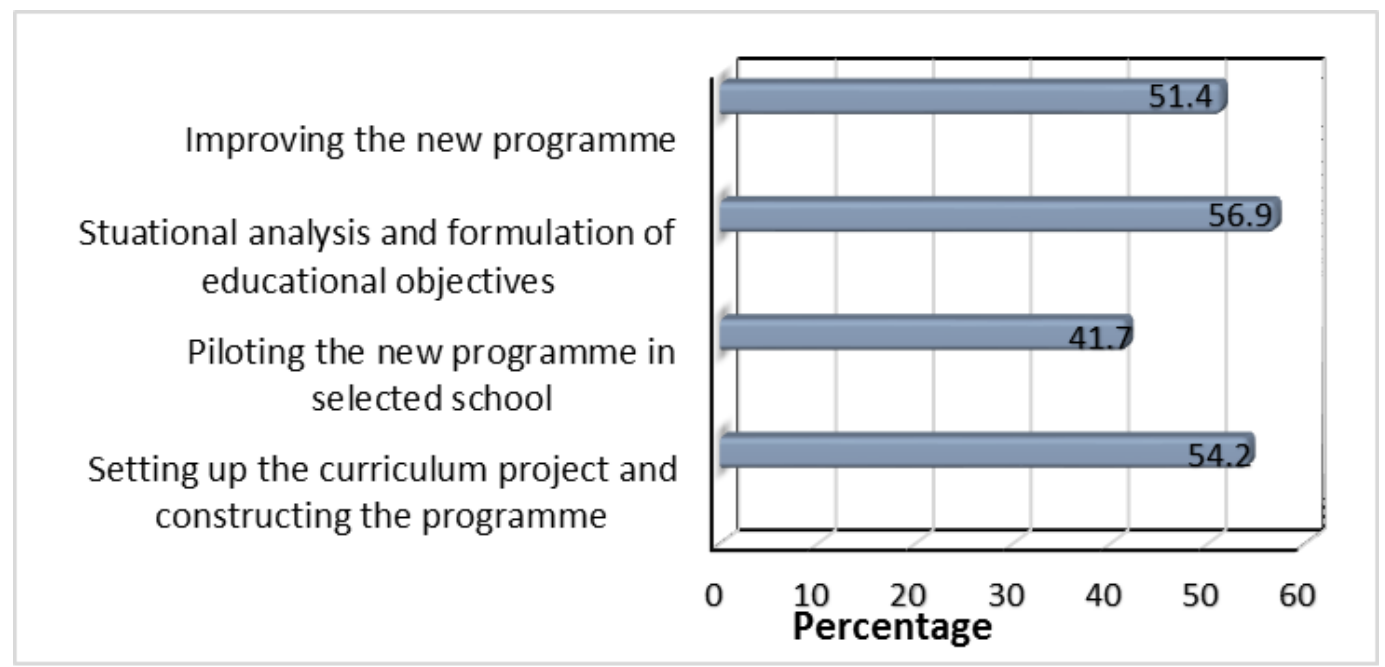

Figure 2. Percentage Distribution of Stages of Teacher Involvement in Curriculum Development

Other stages that emerged included changing the syllabi and the whole set up of the curriculum, advertising and training of teachers who were on teaching practice about the content of what was in the curriculum. Some teachers also indicated that secondary school teachers should be consulted from the beginning of the curriculum development process.

\subsection{Suggested Ways That Would Guarantee Effective Secondary School Teacher Participation}

Teacher participation in the development of the curriculum is critical. However, the level of teachers' participation in curriculum development was low, hence, it was vital to identify ways that would guarantee effective secondary school teacher participation. In this regard, the teachers' questionnaire was designed to seek information from secondary school teachers on their views of different ways which would guarantee effective secondary school teacher participation in the development of the curriculum.

The responses indicated that most teachers should be involved throughout the curriculum development process. Teachers explained that the teachers to participate in the curriculum development process should represent subject teachers, section heads and head of departments. One teacher suggested that;

The Curriculum Development Center should device a deliberate programme to randomly select a lot of teachers from different departments to participate in their seminars and workshops.

Another teacher also suggested decentralizing the curriculum development process by allowing teachers to make an input up to school level. For instance, a teacher noted that;

Participation can be improved by letting provinces, districts and schools put in their input and come up with one comprehensive report, from schools, districts and provinces.

Similarly, another respondent stated that;

The involvement of teachers should start at school level.

Additionally, some teachers suggested that the Curriculum Development Center (CDC) should be open to teachers for their suggestions, giving teachers the CDC programmes, allowing increased teacher participation in curriculum issues and making it more interactive. For instance, one teacher suggested that;

Holding seminars or workshops for HoDs who will submit suggestions from respective teachers will guarantee a proficient secondary school teacher participation in the development of secondary school curriculum.

Other strategies included continuous sensitization through continuous professional development workshops, in-service training and improvement of communication channels. Funding and improved incentives was one strategy for effective teacher participation that emerged among some of the respondents. 


\subsection{Possible Roles That Secondary School Teachers Can Play in the Development of the School Curriculum}

Given that most teachers were willing to participate in the curriculum development process and that suggested strategies to ensure effective teacher participation in the curriculum development were brought forth, it was imperative to establish possible roles that teachers felt they could take up in the curriculum development process. In the teachers'questionnaire a research item sought information on their views of important roles that they could play in the curriculum development process. Similar information was sought from secondary school head teachers during an interview. In response, teachers suggested important roles they would play in the development of the curriculum that when applied would lead to their active involvement in curriculum design. Firstly, most teachers suggested direct involvement in the development of the curriculum. In connection with this, a teacher noted that;

To avoid challenges that are encountered, teachers should be given an opportunity to develop the curriculum so that it becomes easier to implement it.

Other teachers indicated that teachers would play an important role in;

Contributing ideas on how they would want the content of the curriculum to be revised and suggest the times or durations that are convenient for them.

We know the type of pupils that we deal with so we know how certain subjects can be understood better than the ones that are copied elsewhere.

One head teacher emphasized that;

I think teachers as they are teaching they know which areas are supposed to be revised and improved. Teachers also know which areas are supposed to be taught first and last but you find if they are not involved, the people that come up with that document have most times mixed up things.

Similarly, a respondent noted that teachers would play an important;

By submitting their observations based on their experiences in the classroom and how well the learners could benefit from the curriculum

Secondly, the provision of materials and information was one of the roles that surfaced as a possible role teachers would play. Similarly, some teachers noted that they would assist to suggest the gaps that they had observed as they taught their lessons and make submissions such as the links between topics, and provision of materials. This is because teachers are the final implementers of the curriculum and would be able to give the history of successful projects and programs. One teacher noted that;

Teachers would give first-hand information on what should be taught or will work as well as give appropriate advice.

Similarly, one head teacher noted that;

I was privileged to have contributed towards the geography book that we are using now, senior geography. It was not all the teachers but they just sampled a few teachers who sat and came up with the book which is currently used so if I am given to teach the subject, I will teach it comfortably so one of the important roles for teachers is to be involved in the writing of the teaching materials such as learner's textbooks.

Another headteacher argued that

Teachers are the ones who implement the policies set by the government and implement the curriculum so they have an important role to play in the development of the curriculum that they will implement.

One head teacher also emphasized that;

You know, as a teacher, we are the ones who go to class, we know the needs for the learners so if a teacher is part of the people that are developing the curriculum, at least I think it would be better when it comes to implementing, the teachers will know the changes that are coming in and the change won't be faced with a lot of resistance. So that is what I feel.

Other possible roles that emerged included improving the programme and piloting it in selected schools. Some teachers also indicated that teachers could provide checks and balances for the curriculum being developed. This was evidenced when one head teacher said that;

I think in terms of scrutinizing the curriculum, teachers would evaluate it better, and also in terms 
of speaking out what works in the field. So I think teachers play an important role in scrutinizing what should be included in the curriculum. And during the pilot stage teachers should be included in evaluating the curriculum and teaching and learning materials before a decision is taken about their appropriateness.

It is clear from the secondary school teachers and head teachers responses that the majority of teachers felt that they had important roles that they could play in the development of the curriculum. The responses indicated that teacher's roles could not only be narrowed to the implementation of the curriculum in schools but should be extended to all the stages of the curriculum development process.

\section{Discussion and Implications}

Teachers play a very important role in the facilitation of learner's acquisition of desirable knowledge, skills, values and attitudes (Mulenga, 2015). It is therefore crucial that teachers are involved and fully participate in the entire curriculum development process due to the vital role and responsibility placed on them during curriculum implementation. Teachers having the knowledge and class experience must contribute to the curriculum development process by conveying their ideas and transmitting the know-how; they must be in the planning stage of what they are going to implement (Baene and Apple, 2007). In line with this, respondents suggested important roles they would play in the development of the curriculum that when applied would lead to their active involvement in curriculum design. Firstly, most teachers suggested direct involvement in the development of the curriculum.

Most teachers suggested that their involvement in the curriculum development process should be throughout the development process with a selection which should represent subject teachers, section heads and HoDs. This finding support a study by Mosothwane (2012) on the role of senior secondary teachers in the development of mathematics curricular in Botswana which proposed the use of school based consultative committees to gather views of teachers and submit them to local curriculum committees who then took them to regional committees and then national curriculum development panel. Cincioglu (2014) also affirmed that teachers play a key role in the phase of planning as there is need for combening their theoretical knowledge and experiential knowledge; since being able to write down learning outcomes require the field knowledge. Teacher's skills and attitudes count for a great deal more in curriculum development than do in the content and methods (Bishop, 1985). It can be noted that teachers are definitely the heart of the matter as earlier mentioned. We can emphasize this once again that whenever there is need for curriculum development, teacher's role and involvement come to the fore of necessity (Carl, 2012). Because teachers are familiar with the classroom situations, their role is deemed central for discovering the gaps and bringing about change and improvement.

Respondents also suggested decentralizing the curriculum development process so as to allow them to make an input at school level. The findings of this study were also supported by a South African study done by Malebye (1999) on teacher's role in curriculum development where teachers proposed workshops, conferences and formation of school committees as avenues for involvement in the curriculum development. In line with this, Carl (2012) emphasized the need to bring the teacher as implementer together with the institution or person involved with the design so that mutual co-operation may be brought about. Additionally, Wadesango (2014) asserted that involving teachers in school based decision making boosts up their commitment, job satisfaction and morale. This in turn would lead to effective curriculum implementation and thus learner performance would be enhanced.

It is evident from this study's findings that teachers have the first-hand knowledge of the ground realities in the classroom and their involvement in the curriculum development process may create an ownership of the curriculum thus providing teachers with the commitment necessary for the success of the curriculum development process. Teachers understand the nature of learning, pose challenging tasks, encourage students to articulate their ideas, set goals for instruction, create appropriate contexts and pose problems that have relevance and meaning to their learners. Involvement of teachers in curriculum development will improve their skills of creating appropriate and effective context for learning (Munazza, 2004). In addition, Oliva (1992) noted that through curriculum development, teachers can discover new ways for providing more effective pupil learning experiences.

Secondly, the provision of materials and information was one of the roles that surfaced as a possible role teachers would play. Similarly, some teachers noted that they would assist to suggest the gaps that they have observed as they teach and make submissions to provide links between topics, and development of instructional materials. This is because teachers are the final implementers of the curriculum and would be able to give the history of successful projects and programs. Mokua (2010) noted that teachers can determine the local learning needs, identify and build 
on existing strengths, utilise local resources, consider a range of models and decide which best suits the situation. Talking about local needs Mulenga and Mukaba (2018:65) for instance noted in their study on the girls' re-entry policy that 'lack of a curriculum of guidance and conseling was also revealed to be one of the challenges faced in the school'. Such gaps in the school curriculum can only be identified by teachers who are in the schools where the curriculum is actually implemented. Other possible roles that emerged included improving the curriculum and piloting it in selected schools. Some teachers also indicated that teachers could provide checks and balances for the curriculum being developed. This can be actualised because teachers have the direct link with the learners hence are better placed to know what can work and what cannot with their knowledge of the classroom experiences.

The views from the secondary school teachers suggested that teachers were central in any curriculum development process which is consistent with the curriculum diffusion theory which guided the study. In line with this, Schubert (1986) extended the role of a curriculum developer from merely developing the curriculum documents to encompass the work of teachers as he considered them as having a key role in developing curriculum in their planning of programmes that influence the knowledge, skills, attitudes and values of their learners. It is on similar grounds that Bishop (1985) and Havelock (1971) advanced the view that the quality of an education system is dependent on its teachers who should initiate, develop and direct pupils learning.

\section{Conclusion}

The scholars in this study noted that secondary school teachers know the kind of learners they deal with since they are the ones who are placed with a very significant role of curriculum implementation and so they are in a better position to provide valuable advice and direction during the curriculum development process on what aspects would work out well and what would not. It can therefore be concluded that secondary school teachers can play a number of important roles in the development of the secondary school curriculum thereby allowing an effective development and implementation of the curriculum. However, in this study it was noted that teachers are not given such chances and thus their voices are only heard as cries in the school wilderness. Teachers know what to teach and how they can contribute to the improvement of the curriculum development processes in Zambia but the system seems to ignore them and only thinks of them at implementation stage. Thus teachers feel that their school and classroom experiences, skills and knowledge are underutilized.

\section{Acknowledgements}

We would like to express our gratitude to the Director, Curriculum and Stardards in the Ministry of General Education in Zambia, for giving us permission to collect data in secondary schools. We would also like to thank the Univesity of Zambia, Staff Development Office, for giving us research funds to conduct this study.

\section{References}

Baene, J. A., \& Apple, M. W. (2007). The case for Democratic schools. In M.W Apple \& J.A. Baene (Eds.), Democratic schools: Lessons in powerful education (1-29). Portsmouth, NH: Heinemann.

Bishop, G. (1985). Curriculum Development: A textbook for Students. London: The Macmillan Press.

Carl, A. E. (2012). Teacher Empowerment through Curriculum Development. Theory into Practice. Kenwyn: Juta Academic press.

Carless, D. (1997). Managing Systemic Curriculum Change: A Critical Analysis of Hong Kong's Target-Oriented Curriculum Initiative. International Review of Education / Internationale Zeitschrift Für Erziehungswissenschaft / Revue Internationale De L'Education, 43(4), 349-366.

Cincioglu, A. (2014). Why to involve teachers in the process of Language curriculum development. Yabana: Instanbul University.

Creswell, J. W. (2009). Research Design: Qualitative, Quantitative and Mixed Methods Approaches. London: Sage Publication.

Hale, J. A. (2008). A Guide to Curriculum Mapping: Planning, Implementation and Sustaining the Process. California: Corwin Press.

Havelock, R. G. (1971). The Utilization of Educational Research and Development. British Journal of Education and 
Technology, 2(2), 84-98. https://doi.org/10.1111/j.1467-8535.1971.tb000552.x

Lawton, D. (1973). Social Change, Educational Theory and Curriculum Planning. London: University of London.

McNeil, J. (2006). Contemporary Curriculum in Thought and Action (6th ed.). Chicago: Wiley Josse-Bass Education.

Mokua, B. (2010). An Evaluation of the curriculum development role of teachers as key Agents in curriculum change. MEd Thesis, North-west University: South Africa.

Mosothwane, M. (2012). The role of senior secondary school mathematics teachers in the development of Mathematics curriculum in Bostwana. International Journal of scientific research in Education, 5(2), 117-129.

Mulenga, I. M. (2015). English Language Teacher Education Curriculum Designing: A Mixed Methods Analysis of the Programme at the University of Zambia. PhD Thesis. The University of Zambia.

Mulenga, I. M., \& Luangala, J. R. (2015). Curriculum Design in Contemporary Teacher Education: What makes Job Analysis a vital preliminary ingredient? International Journal of Humanities Social Sciences and Education, 2(1), 39-51.

Mulenga, I. M., \& Mukaba, B. (2018). Policy and Practice: Roles of the Guidance and Counseling Teachings in the Implementation of the Girls' Re-entry Policy in selected Schools in Lusaka, Zambia. Journal of Education, 9(2), 57-67.

Munazza, A. (2004). Analysis of curriculum progress and development of a model for secondary school level in Pakestan. University of Arid Agriculture: Rawal Pindi.

Olive, P. F. (1992). Developing the curriculum. Georgia: Little Brown Company Limited.

Ondiek, P. E. (1986). Curriculum Development: Alternatives in Educational Theory and Practice. Kisumu: Lake Publishers and Enterprises.

Ornstein, A. C., \& Hunkins, F. P. (2009). Curriculum: Foundations, Principles and Issues (4th ed.). London: Pearson Education.

Posner, G. (2004). Analyzing the Curriculum (3rd ed.). London: McGraw Hill.

Schubert, W. H. (1986). Curriculum: Perspectives, paradigm and possibility. New York: Macmillan Publishing Company.

Wadesango, N. (2014). Extent of teacher participation in school based fund raising activities. Anthropologist, 17(2), 319-325. https://doi/abs/10.1080/09720073.2014.11891440

Weber, S. (2011). The Power of the Taught Curriculum. Retrieved from http://edge.used.org/The-power-of-the-taught-curriculum/blog/3326074/127568.ht ml

Wiles, J. (2005). Curriculum Essentials: A Resource for Educators (2nd ed.). Boston: Pearson Education. 